\title{
Reduced prevalence of placental malaria in primiparae with blood group $\mathrm{O}$
}

\author{
George Bedu-Addo ${ }^{1}$, Prabhanjan P Gai ${ }^{2}$, Stefanie Meese ${ }^{2}$, Teunis A Eggelte ${ }^{3}$, Kumarasamy Thangaraj ${ }^{4}$ \\ and Frank P Mockenhaupt ${ }^{2^{*}}$
}

\begin{abstract}
Background: Blood group $O$ protects African children against severe malaria and has reached high prevalence in malarious regions. However, its role in malaria in pregnancy is ambiguous. In 839 delivering Ghanaian women, associations of $\mathrm{ABO}$ blood groups with Plasmodium falciparum infection were examined.

Methods: Plasmodium falciparum infection was diagnosed in placental blood samples by microscopy and PCR assays. Present or past infection was defined as the detection of parasitaemia or haemozoin by microscopy, or a positive PCR result. Blood groups were inferred from genotyping rs8176719 (indicating the $O$ allele) and rs8176746/ rs8176747 (distinguishing the B allele from the A allele).

Results: The majority of women had blood group $O$ (55.4\%); present or past $P$. falciparum infection was seen in $62.3 \%$ of all women. Among multiparae, the blood groups had no influence on P. falciparum infection. In contrast, primiparae with blood group $\mathrm{O}$ had significantly less present or past infection than women with non-O blood groups (61.5 vs $76.2 \%, P=0.007$ ). In multivariate analysis, the odds of present or past placental $P$. falciparum infection were reduced by $45 \%$ in blood group O primiparae (aOR, 0.55 [95\% Cl, 0.33-0.94]).

Conclusions: The present study shows a clear protective effect of blood group $\mathrm{O}$ against malaria in primiparae. This accords with findings in severe malaria and in vitro results. The data underline the relevance of host genetic protection among primiparae, i.e. the high-risk group for malaria in pregnancy, and contribute to the understanding of high $\mathrm{O}$ allele frequencies in Africa.
\end{abstract}

\section{Background}

Plasmodium falciparum malaria has long been suggested to influence the global distribution of the ABO blood groups [1], similar to the selection of the malariaprotective sickle cell gene in endemic regions [2]. In fact, blood group $\mathrm{O}$ is particularly common in malarious regions, e.g. sub-Saharan Africa [3,4], and confers protection against potentially fatal severe malaria across African populations [5-8]. In addition, various in vitro observations and functional hypotheses support a protective role of blood group $\mathrm{O}$ (reviewed by $[3,4,9]$ ).

In contrast, findings are notably ambiguous with respect to the impact of the $\mathrm{ABO}$ system on malaria in pregnancy. Pregnant women - particularly primiparae are a high risk group for $P$. falciparum infection and

\footnotetext{
* Correspondence: frank.mockenhaupt@charite.de

${ }^{2}$ Institute of Tropical Medicine and International Health, Charité - University Medicine Berlin, Berlin, Germany

Full list of author information is available at the end of the article
}

malaria. In areas of high transmission, malaria in pregnancy is frequently asymptomatic but consequences involve anaemia, abortion, stillbirth, low birth weight (LBW), preterm delivery (PTD), and, annually, up to 200,000 infant deaths [10]. In pregnant women, specific expression variants of the parasite's $P$. falciparum erythrocyte membrane protein-1 (PfEMP1) mediate adhesion to the placental syncytiotrophoblast (the epithelial lining of the intervillous space) and thereby placental sequestration of infected erythrocytes, deposition of haemozoin (malaria pigment), and, commonly, the local accumulation of inflammatory cells [11]. In highly endemic regions, specific immunity against these pregnancyassociated parasites is particularly low in primigravidae, and acquired only with successive pregnancies, which goes along with declining infection prevalence and clinical manifestation [10-12]. In The Gambia and Malawi, blood group $\mathrm{O}$ was associated with increased odds of placental malaria in primiparae but with a reduced risk in 
multiparae $[13,14]$. In Sudan, blood group O and past placental infection were associated in both primi- and multiparae [15]. In contrast, a Gabonese study reported a trend towards less placental malaria in blood group $\mathrm{O}$ women [16], and in a recent prospective study from Thailand, no association at all between $\mathrm{ABO}$ blood groups and malaria during pregnancy was observed [17]. Against this background of conflicting results, the present study aimed at examining the influence of blood group $\mathrm{O}$ on $P$. falciparum infection among pregnant women in hyper- to holo-endemic Ghana using PCR for blood group genotyping.

\section{Methods}

Eight-hundred and thirty-nine women with live singleton delivery were recruited from January 2000 through January 2001 at the Presbyterian Mission Hospital in Agogo, Ghana. The study protocol was approved by the Committee on Human Research Publications and Ethics, School of Medical Sciences, University of Science and Technology, Kumasi, and informed written consent was obtained from all women. Agogo is a community of some 30,000 inhabitants located in the forested hills of Asante Akim North District. Subsistence farming, trade and mining are the main income sources in that region, and malaria is hyper- to holo-endemic [18]. Study procedures and the characteristics of the largely asymptomatic participants have been described in detail elsewhere [12]. In brief, women were clinically examined, socio-economic data documented, and intervillous and venous blood samples were collected into EDTA. Malaria parasites in postdelivery placental and venous samples were counted microscopically on Giemsa-stained thick blood films per 100 high-power fields and 500 white blood cells, respectively. Placental parasite densities were expressed as parasites $/ 100$ fields and peripheral ones as parasites $/ \mu \mathrm{L}$ assuming a mean white blood cell count of $8,000 / \mu \mathrm{L}$. Leukocyte-associated haemozoin in placental samples was recorded. Following DNA extraction (QIAmp, Qiagen, Hilden, Germany), nested P. falciparum-specific PCR assays were performed [19]. Present or past placental P. falciparum infection was defined as the presence of placental parasitaemia or haemozoin by microscopy, or a positive $P$. falciparum PCR result on placental samples. Plasma concentrations of pyrimethamine, at that time recommended for malaria chemoprophylaxis in pregnancy, and of chloroquine were measured by ELISA assays [20] with limits of detection of $10 \mathrm{ng} / \mathrm{mL}$ and $5 \mathrm{ng} / \mathrm{ml}$, respectively. Haemoglobin $(\mathrm{Hb})$ was measured by a HemoCue photometer (Ångelholm, Sweden). Anaemia was defined as $\mathrm{Hb}<11 \mathrm{~g} / \mathrm{dL}$. Birth weight and gestational age were assessed within 24 hours after delivery. LBW was defined as a birth weight $<2500$ g. PTD was defined as a gestational age $<37$ weeks applying the Finnström score which correctly estimates gestational age $( \pm 3$ weeks $)$ in $>95 \%$ of infants [21].

Three loci on the $A B O$ gene, namely rs8176719, rs 8176746 , and rs 8176747 were typed by melting curve analysis employing the LightCycler 480 device (Roche Diagnostics, Mannheim, Germany) and using commercially available primers and probes (TIB Molbiol, Berlin, Germany). ABO blood groups were inferred from rs8176719 (indicating the $O$ allele) and from rs8176746/ rs8176747 (distinguishing the $B$ allele from the $A$ allele) [22]. In case of ambiguous typing results $(n=38)$, PCRgenerated fragments containing the polymorphisms of interest were subjected to sequencing (Eurofins, Berlin, Germany).

Continuous variables were compared between groups by $t$-test, analysis of variance, Mann-Whitney $U$-test, and Kruskal-Wallis test as applicable. Associations of blood groups with P. falciparum infection, anaemia, LBW, and PTD were identified by $\chi^{2}$-test, and odds ratios (ORs) and 95\% confidence intervals (95\% CIs) calculated. Adjusted ORs (aORs) were derived from logistic regression models with stepwise backward removal of factors not associated in multivariate analysis $(P>0.05)$. For placental malaria, previously identified associated factors were a priori included, i.e. delivery in rainy season, age and plasma pyrimethamine concentrations [12]. A $P$-value of $<0.05$ was considered statistically significant.

\section{Results}

ABO genotyping was successful in 827 of 839 (98.6\%) women with a live singleton delivery. The majority of women (55.4\%) had blood group O. Blood groups B, A, and $A B$ were present in 22.6, 18.0, and $4.0 \%$, respectively. Blood groups were in Hardy-Weinberg equilibrium; genotypes are detailed in Table 1. Plasma concentrations of pyrimethamine, representing chemoprophylaxis, were observed in $36.0 \%(163 / 453)$ of women with blood group $\mathrm{O}$, and in $33.3 \%(119 / 357)$ of women with non-O blood groups $(P=0.43$; chloroquine plasma concentrations, $24.3 \%(110 / 453)$ vs. $20.2 \%$ (72/ 357), $P=0.16$ ).

Evidence of present or past $P$. falciparum infection in placental samples (parasitaemia or haemozoin by

Table 1 ABO genotypes in 827 delivering Ghanaian women

\begin{tabular}{lll}
\hline Phenotype & Genotype & No (\%) \\
\hline O & O O* & $458(55.4)$ \\
B & B O & $169(20.4)$ \\
& B B & $18(2.2)$ \\
A & A O & $136(16.4)$ \\
& A A & $13(1.6)$ \\
AB & A B & $33(4.0)$ \\
\hline${ }^{*}$, includes genotypes $\mathrm{OO}^{24}(n=30), \mathrm{O}^{24} \mathrm{O}^{24}(n=1)$, and $\mathrm{O}^{2} \mathrm{O}^{2}(n=1)$.
\end{tabular}


microscopy, or a positive $P$. falciparum PCR result) was seen in $62.3 \%(515 / 827)$ of all women. This figure was significantly lower in women with blood group O (59.0\%, $270 / 458$ ) than in women with non-O blood groups (66.4\%, 245/369; $P=0.03)$. Notably, this difference was pronounced among primiparae $(61.5 \%$ vs. $76.2 \%, P=$ 0.007 ) but insignificant among multiparae (Table 2). Further analysis therefore focused on the 300 primiparous women. Among these, the prevalence of infection (regardless of diagnostic tool) appeared to be lower in women with blood group $\mathrm{O}$ than in any of the non-O blood groups. Based on parasite detection by microscopy, this difference was only small. Likewise, neither placental nor peripheral blood parasite densities correlated with the blood groups (e.g., placental parasite densities in blood group O versus non-O primiparae: 127 (95\% CI, 74-216) vs. 102 (51-204) parasites/100 high-power fields, $P=$ $0.63)$. In contrast, the reduced infection prevalence among blood group $\mathrm{O}$ primiparae was obvious taking into account PCR results, and even more so when considering placental haemozoin (Table 3). In multivariate analysis, the odds of present or past placental P. falciparum infection were reduced by $45 \%$ in primiparae with blood group $\mathrm{O}$ (Table 3), adjusting for known predictors of placental infection in this group [12], i.e. years of age (aOR, 0.92 [95\% CI, 0.86-0.99]), delivery in the rainy season (aOR, 1.76 [95\% CI, 1.06-2.92]), and presence of pyrimethamine in plasma (indicating compliance with chemoprophylaxis; aOR, 0.60 [95\% CI, 0.35-1.00]). Breakdown by placental infection status [23] revealed that blood group $\mathrm{O}$ tended to protect particularly against late infections (both parasites and pigment present), while - combining microscopy and PCR results - the impact on microscopic (i.e. visible parasites) and submicroscopic infections (i.e. detectable by PCR only) was similar (Table 3).

Small numbers prevented a meaningful attribution of infection risks to individual genotypes. Nevertheless, present or past placental infection was observed in $88.9 \%(16 / 18)$ of primiparae with homozygous non-O genotypes, in $74.1 \%(80 / 108)$ of O-heterozygous women, and in $61.5 \%(107 / 174)$ of first-time delivering women with blood group $\mathrm{O}\left(\mathrm{c}^{2}\right.$ trend $\left.=8.7, P=0.003\right)$. Correspondingly, the $O$ allele was significantly less frequent in primiparae with present or past placental infection than in those without $(0.72$ vs $0.84, P=0.003)$.

In multiparae, none of the above malaria-protective features of blood group $\mathrm{O}$ were discernible; blood group $\mathrm{A}$ even tended to come along with lower infection prevalence (Table 2). Particularly, already in secundiparae, present or past placental infection occurred at similar prevalence in women with blood group $\mathrm{O}$ and in the nonO group (66.0\% (70/106) vs 69.2\% (54/78), $P=0.65)$.

Blood group $\mathrm{O}$ was furthermore associated with reduced odds of maternal anaemia among all women, and among primiparae in particular (Table 4). This was due to the difference in women without placental malaria, i.e. only $10.5 \%$ (7/67) of non-malarious blood group O primiparae in this group were anaemic as compared to $33.3 \%$ $(10 / 30)$ of their non-O peers $(P=0.006)$ whereas the difference was small and not significant among primiparae with evidence of present or past infection (44.9\%, 48/107 vs $52.1 \%, 50 / 96, P=0.30)$. Likewise, the proportions of malaria-associated LBW or preterm delivery did not differ significantly between $\mathrm{O}$ and non-O blood groups, neither in primiparae nor in multiparae.

\section{Discussion}

In the present study from Ghana, almost two in three women had evidence of present or past placental P. falciparum infection. In this highly endemic setting, blood group $\mathrm{O}$ was associated with protection against placental malaria among primiparae but not in multiparae, and particularly against late or chronic infections, i.e., infections characterized by the presence of pigment. This

Table 2 Prevalence of Plasmodium falciparum infection according to blood group and parity

\begin{tabular}{|c|c|c|c|c|c|c|c|c|c|c|}
\hline & \multicolumn{5}{|c|}{ Blood group, primiparae } & \multicolumn{5}{|c|}{ Blood group, multiparae } \\
\hline & \multirow[t]{2}{*}{0} & \multicolumn{4}{|c|}{ Non-O } & \multirow[t]{2}{*}{0} & \multicolumn{4}{|c|}{ Non-O } \\
\hline & & All & B & A & $A B$ & & All & B & A & $A B$ \\
\hline No. & 174 & 126 & 72 & 46 & 8 & 283 & 237 & 111 & 102 & 24 \\
\hline \multicolumn{11}{|c|}{ P. falciparum infection, placental blood (\%) } \\
\hline Microscopy positive & 42.5 & 50.0 & 52.8 & 43.5 & 62.5 & 30.0 & 27.0 & 31.5 & 21.6 & 29.2 \\
\hline Haemozoin positive & 36.2 & $50.8^{*}$ & $52.8^{*}$ & 50.0 & 37.5 & 24.0 & 24.9 & 28.8 & 17.6 & 37.5 \\
\hline PCR positive & 60.3 & 70.6 & 65.3 & $76.1^{*}$ & 87.5 & 55.5 & 58.2 & 60.4 & 54.9 & 62.5 \\
\hline Any positive finding ${ }^{\dagger}$ & 61.5 & $76.2^{*}$ & 69.4 & $84.8^{*}$ & 87.5 & 57.6 & 61.6 & 64.0 & 57.8 & 66.7 \\
\hline \multicolumn{11}{|c|}{ P. falciparum infection, peripheral blood (\%) } \\
\hline Microscopy positive & 24.1 & 29.4 & 33.3 & 26.1 & 12.5 & 17.0 & 11.4 & 14.4 & $8.8^{*}$ & 8.3 \\
\hline PCR positive & 54.6 & 65.1 & 62.5 & 69.6 & 62.5 & 50.5 & 49.4 & 52.3 & 45.1 & 54.2 \\
\hline
\end{tabular}

*Comparison to blood group $\mathrm{O}, \mathrm{P}<0.05 ;{ }^{\dagger}$, parasitaemia or haemozoin by microscopy, or positive PCR. Parity data were missing for seven women. 


\begin{tabular}{|c|c|c|c|c|c|c|}
\hline \multirow[t]{2}{*}{ Placental infection status } & \multicolumn{2}{|c|}{ Blood group } & \multirow[t]{2}{*}{ OR $(95 \% \mathrm{Cl})$} & \multirow[t]{2}{*}{$P$} & \multirow[t]{2}{*}{$\mathrm{aOR}^{*}(95 \% \mathrm{Cl})$} & \multirow[t]{2}{*}{$P$} \\
\hline & $\overline{0}$ & Non-O & & & & \\
\hline Microscopy positive (\%) & 42.5 & 50.0 & $0.74(0.45-1.20)$ & 0.20 & $0.80(0.49-1.28)$ & 0.35 \\
\hline Haemozoin positive (\%) & 36.2 & 50.8 & $0.55(0.34-0.90)$ & 0.01 & $0.61(0.37-0.98)$ & 0.04 \\
\hline PCR positive (\%) & 60.3 & 70.6 & $0.63(0.38-1.06)$ & 0.07 & $0.68(0.41-1.13)$ & 0.14 \\
\hline Any positive finding $(\%)^{\dagger}$ & 61.5 & 76.2 & $0.50(0.29-0.86)$ & 0.007 & $0.55(0.33-0.94)$ & 0.03 \\
\hline \multicolumn{7}{|c|}{ Microscopic infection status (\%) } \\
\hline Pigment only & 5.2 & 8.7 & $0.47(0.16-1.32)$ & 0.11 & $0.62(0.23-1.67)$ & 0.35 \\
\hline Pigment plus parasites & 31.0 & 42.1 & $0.58(0.34-1.0)$ & 0.04 & $0.64(0.38-1.09)$ & 0.10 \\
\hline Parasites only & 11.5 & 7.9 & $1.14(0.46-2.85)$ & 0.75 & $1.33(0.55-3.20)$ & 0.52 \\
\hline \multicolumn{7}{|l|}{ PCR-based infection status (\%) } \\
\hline Submicroscopic & 17.8 & 22.2 & $0.56(0.28-1.14)$ & 0.08 & $0.59(0.30-1.14)$ & 0.12 \\
\hline Microscopic & 42.5 & 50.0 & $0.60(0.34-1.04)$ & 0.05 & $0.64(0.37-1.11)$ & 0.12 \\
\hline
\end{tabular}

Odds ratios are calculated against the respective non-infected reference group.

*Adjusted for age, rainy season, and presence of pyrimethamine in plasma (indicating intake of chemoprophylaxis).

${ }^{\dagger}$ Parasitaemia or haemozoin by microscopy, or positive PCR.

finding accords with the clearly protective role of blood group $\mathrm{O}$ in severe malaria [5-8] and the moderately beneficial impact of blood group $\mathrm{O}$ in many studies on uncomplicated malaria (reviewed by $[3,4,9]$ ). Severe childhood malaria and malaria in pregnancy differ largely in terms of pathophysiology, immunity and clinical manifestation [10-12], but primiparae to some extent resemble young children with respect to a lack or an insufficient degree of protective immune mechanisms against $P$. falciparum. In pregnant women, $P$. falciparum-infected erythrocytes sequester in the intervillous space by adhering to ligands on the syncytiotrophoblast, followed by the local accumulation of haemozoin and inflammatory cells. Specific antibodies capable of blocking parasite adhesion prevent this placental malaria only after successive pregnancies exposed to $P$. falciparum infection $[11,24,25]$. This likely explains why protection against $P$. falciparum infection due to blood group $\mathrm{O}$ in the present study was limited to the relatively immunenaive group of primiparae. At higher parity, the effects of adaptive immunity may override the protection afforded by blood group $\mathrm{O}$.

Notably, however, two studies from The Gambia and Malawi have reported results contrasting the present finding, i.e. an increased risk of active placental malaria in blood group $\mathrm{O}$ primiparae and a reduced risk in multiparae $[13,14]$. The reason for this disagreement is unclear but may involve the classification of placental malaria by histopathological diagnosis in these previous studies and by blood film microscopy and PCR in the present. Remarkably, in both previous studies, past infections (presence of pigment only) tended to be reduced in blood group $\mathrm{O}$ primiparae. In the present study, much of the observed associations was based on the lowered presence of haemozoin but microscopically visible parasites also tended to be reduced in group $\mathrm{O}$ primiparae (Table 3). Sensitive PCR assays in the present study, considered to detect only viable parasites [26], only shifted this difference between blood groups to a higher prevalence level and, interestingly, the reduced infection rate in blood group $\mathrm{O}$ primiparae was observed for both microscopic and submicroscopic infections. This is in line with the lack of effect of the blood groups on parasite density observed in the present study. Part of the conflicting results with and between previous studies may result from small samples sizes $[13,15,16]$ as well as from low prevalence of infection [15-17] in previous studies. Notably, however, in one small study from Gabon, blood group O tended to protect against placental malaria, with a larger effect in primiparae than in

Table 4 Anaemia, low birth weight, and preterm delivery separated by blood group and parity

\begin{tabular}{|c|c|c|c|c|c|c|}
\hline \multirow[t]{2}{*}{ Parameter } & \multicolumn{2}{|l|}{ All } & \multicolumn{2}{|l|}{ Primiparae } & \multicolumn{2}{|l|}{ Multiparae } \\
\hline & Blood group 0 & Non-O blood groups & 0 & Non-O blood groups & 0 & Non-O blood groups \\
\hline Anaemia $(\%, n / n)$ & $31.7(145 / 458)$ & $39.6(146 / 369)^{*}$ & $31.6(55 / 174)$ & $47.6(60 / 126)^{\dagger}$ & $31.8(90 / 283)$ & $35.9(85 / 237)$ \\
\hline LBW $(\%, n / n)$ & $14.6(67 / 458)$ & $17.9(66 / 369)$ & $23.0(40 / 174)$ & $30.2(38 / 126)$ & $9.5(27 / 283)$ & $11.4(27 / 237)$ \\
\hline PTD $(\%, n / n)$ & $17.8(81 / 454)$ & $20.3(74 / 365)$ & $24.7(43 / 174)$ & $28.6(36 / 126)$ & $13.6(38 / 279)$ & $15.8(37 / 234)$ \\
\hline
\end{tabular}

${ }^{*}, P=0.02 ;{ }^{\dagger}, P=0.005$ 
multiparae [16]. In almost 1,500 women in Thailand, weekly malaria screening by peripheral blood films did not show any effect of the $\mathrm{ABO}$ blood groups on malaria episodes (occurring in 30\% of women) [17]. However, peripheral blood film microscopy in pregnant women has a notoriously poor sensitivity [27], only $1 \%$ of placentas were malaria positive, and the majority of malaria episodes were due to Plasmodium vivax. Therefore, it is questionable whether these findings from Thailand can be compared with the African studies. Blood group $\mathrm{O}$ in the present study was also associated with reduced odds of anaemia, particularly in primiparae. Protection from malaria-related anaemia in individuals with blood group O has been observed before [28] but, remarkably, this was not the case in the present study, in which, rather, anaemia was less common among non-infected blood group $\mathrm{O}$ women. This finding may reflect the cumulative effect over time of reduced malaria in blood group $\mathrm{O}$ primiparae. Longitudinal studies will be needed to address this question.

As a limitation of the present study, protection by blood group $\mathrm{O}$ was statistically significant only when considering placental haemozoin or when combining results of all diagnostic means (although microscopic data showed accordant trends). Statistically significant findings were observed in the relatively small group of 300 primiparae of whom 174 had blood group O. The study was sufficiently powered to detect an influence of blood group $\mathrm{O}$ on present or past infection but power declined with declining diagnostic sensitivity, i.e. prevalence of infection. Limited sample sizes in subgroups may thus have interfered with the analysis of infection risks in individual genotypes and of potential modification of malaria-related outcomes, e.g., LBW. Also, data on some potentially interfering factors were not available, e.g., bed net use or transfusions. This should be kept in mind when interpreting the data.

The hypotheses on why blood group $\mathrm{O}$ protects from malaria, and from severe malaria in particular, include aspects of differential attractiveness to Anopheles vectors, shared $\mathrm{ABO}$ antigens with P. falciparum, impaired merozoite penetration as well as reduced cyto-adherence (reviewed by $[3,4,9])$. The A and B antigens are erythrocyte surface trisaccharides [22] and receptors for rosetting, i.e. the binding of $P$. falciparum-infected red blood cells (RBCs) to uninfected erythrocytes (an in vitro sign of parasites causing severe malaria) [5]. Binding of the parasite ligand, PfEMP1, to the $\mathrm{A}$ antigen has been shown [29]. In blood group $\mathrm{O}$, the disaccharide $\mathrm{H}$ antigen is produced instead of $\mathrm{A}$ and $\mathrm{B}$ antigens [22], and $P$. falciparum-infected RBCs form smaller and less firm rosettes than in non-O RBCs [29]. In fact, the protective effect of blood group $\mathrm{O}$ against severe malaria has been shown to operate through the mechanism of reduced $P$. falciparum rosetting [5]. However, rosetting is rarely observed in placental P. falciparum isolates [30] and the PfEMP1 domain mediating binding to ligands on the syncytiotrophoblast differs from the binding domain involved in rosetting [29,31,32]. Nevertheless, ABOdependent differences in cyto-adherence may still be relevant in placental malaria (reviewed by [4]): The molecules on the syncytiotrophoblast to which pregnancyspecific $P$. falciparum strains bind, i.e. chondroitin sulphate A (CSA) and hyaluronic acid [33,34], are structurally related to the $\mathrm{A}$ antigen which gives rise to the possibility that adhesion of infected RBCs to the syncytiotrophoblast may be influenced by $\mathrm{ABO}$ polymorphisms. Also, the placental proteoglycan thrombomodulin mediates part of the binding of infected RBCs [35]. Thrombomodulin and other molecules involved in cytoadhesion, e.g., von Willebrandt factor, are affected by the ABO phenotype [36]. Recently, enhanced macrophagemediated phagocytosis of $P$. falciparum-infected O-RBCs has been shown [37]. Considering that many women with placental malaria show a substantial inflammatory infiltrate in the intervillous space, composed mainly of monocytes and macrophages [38], ABO-dependent clearance of infected RBCs could partially explain the finding of the present study of less placental malaria in women with blood group $\mathrm{O}$.

\section{Conclusion}

The present study demonstrates a protective influence of blood group $\mathrm{O}$ against $P$. falciparum infection in primiparae living in an area of high malaria endemicity. Considering the consequences of placental malaria in terms of infant mortality, the influence of the $\mathrm{ABO}$ polymorphism on malaria in pregnancy may contribute to the high frequencies of the $\mathrm{O}$ allele in sub-Saharan Africa.

\section{Competing interests}

The authors declare that they have no competing interests.

\section{Authors' contributions}

GBA, KT, and FPM designed the study. GBA, TAE and FPM were responsible for patient recruitment, clinical and laboratory examinations. PPG and SM did the PCR analyses, TAE and KT contributed to data interpretation, and FPM did the statistical analyses. GBA and FPM wrote the paper with major contributions of the other authors. All authors read and approved the final manuscript.

\section{Acknowledgements}

We thank the participating women and the midwives and administration at Agogo Hospital. This work was supported by Charité-Universitätsmedizin Berlin (grants 2000-512, 2001-613) and Deutsche Forschungsgemeinschaft (grants GRK1673/B7(1) to SM and B7(2) to PPG).

\section{Author details}

'Department of Medicine, Komfo Anoyke Teaching Hospital, School of Medical Sciences, Kwame Nkrumah University of Science and Technology, Kumasi, Ghana. ${ }^{2}$ Institute of Tropical Medicine and International Health, Charité - University Medicine Berlin, Berlin, Germany. ${ }^{3}$ Division of Infectious Diseases, Tropical Medicine and AIDS, Academic Medical Centre, Amsterdam, The Netherlands. ${ }^{4}$ Centre for Cellular and Molecular Biology, Hyderabad, India. 
Received: 17 June 2014 Accepted: 21 July 2014

Published: 28 July 2014

\section{References}

1. Athreya BH, Coriell LL: Relation of blood groups to infection. I. A survey and review of data suggesting possible relationship between malaria and blood groups. Am J Epidemiol 1967, 86:292-304.

2. Kwiatkowski DP: How malaria has affected the human genome and what human genetics can teach us about malaria. Am J Hum Genet 2005, 77:171-192.

3. Cserti $\mathrm{CM}$, Dzik WH: The ABO blood group system and Plasmodium falciparum malaria. Blood 2007, 110:2250-2258.

4. Loscertales MP, Owens S, O'Donnell J, Bunn J, Bosch-Capblanch X, Brabin BJ: ABO blood group phenotypes and Plasmodium falciparum malaria: unlocking a pivotal mechanism. Adv Parasitol 2007, 65:1-50.

5. Rowe JA, Handel IG, Thera MA, Deans AM, Lyke KE, Koné A, Diallo DA, Raza A, Kai O, Marsh K, Plowe CV, Doumbo OK, Moulds JM: Blood group O protects against severe Plasmodium falciparum malaria through the mechanism of reduced rosetting. Proc Natl Acad Sci U S A 2007, 104:17471-17476

6. Fry AE, Griffiths MJ, Auburn S, Diakite M, Forton JT, Green A, Richardson A, Wilson J, Jallow M, Sisay-Joof F, Pinder M, Peshu N, Williams TN, Marsh K, Molyneux ME, Taylor TE, Rockett KA, Kwiatkowski DP: Common variation in the $A B O$ glycosyltransferase is associated with susceptibility to severe Plasmodium falciparum malaria. Hum Mol Genet 2008, 17:567-576.

7. Jallow M, Teo YY, Small KS, Rockett KA, Deloukas P, Clark TG, Kivinen K, Bojang KA, Conway DJ, Pinder M, Sirugo G, Sisay-Joof F, Usen S, Auburn S, Bumpstead SJ, Campino S, Coffey A, Dunham A, Fry AE, Green A, Gwilliam R, Hunt SE, Inouye M, Jeffreys AE, Mendy A, Palotie A, Potter S, Ragoussis J, Rogers J, Rowlands K, et al: Genome-wide and fine-resolution association analysis of malaria in West Africa. Nat Genet 2009, 41:657-665.

8. Timmann C, Thye T, Vens M, Evans J, May J, Ehmen C, Sievertsen J, Muntau B, Ruge G, Loag W, Ansong D, Antwi S, Asafo-Adjei E, Nguah SB, Kwakye KO, Akoto AO, Sylverken J, Brendel M, Schuldt K, Loley C, Franke A, Meyer CG, Agbenyega T, Ziegler A, Horstmann RD: Genome-wide association study indicates two novel resistance loci for severe malaria. Nature 2012, 489:443-446.

9. Rowe JA, Opi DH, Williams TN: Blood groups and malaria: fresh insights into pathogenesis and identification of targets for intervention. Curr Opin Hematol 2009, 16:480-487.

10. Desai M, ter Kuile FO, Nosten F, Asamoa K, Brabin B, Newman RD: Epidemiology and burden of malaria in pregnancy. Lancet Infect Dis 2007, 7:93-104.

11. Rogerson SJ, Hviid L, Duffy PE, Leke RF, Taylor DW: Malaria in pregnancy: pathogenesis and immunity. Lancet Infect Dis 2007, 7:105-117.

12. Mockenhaupt FP, Bedu-Addo G, von Gaertner C, Boyé R, Fricke K, Hannibal I, Karakaya F, Schaller M, Ulmen U, Acquah PA, Dietz E, Eggelte TA, Bienzle U: Detection and clinical manifestation of placental malaria in southern Ghana. Malar J 2006, 5:119.

13. Loscertales MP, Brabin BJ: ABO phenotypes and malaria related outcomes in mothers and babies in The Gambia: a role for histo-blood groups in placental malaria? Malar J 2006, 5:72.

14. Senga E, Loscertales MP, Makwakwa KE, Liomba GN, Dzamalala C, Kazembe $\mathrm{PN}$, Brabin $\mathrm{BJ}$ : $\mathrm{ABO}$ blood group phenotypes influence parity specific immunity to Plasmodium falciparum malaria in Malawian women. Malar $J$ 2007, 6:102.

15. Adam I, Babiker S, Mohmmed AA, Salih MM, Prins MH, Zaki ZM: ABO blood group system and placental malaria in an area of unstable malaria transmission in eastern Sudan. Malar J 2007, 6:1 10.

16. Adegnika AA, Luty AJ, Grobusch MP, Ramharter M, Yazdanbakhsh M, Kremsner PG, Schwarz NG: ABO blood group and the risk of placental malaria in sub-Saharan Africa. Malar J 2011, 10:101.

17. Boel ME, Rijken MJ, Pimanpanarak M, Keereecharoen NL, Proux S, Nosten F, McGready R: No association of phenotypic ABO blood group and malaria during pregnancy. Am J Trop Med Hyg 2012, 87:447-449.

18. Browne EN, Frimpong E, Sievertsen J, Hagen J, Hamelmann C, Dietz K, Horstmann RD, Burchard GD: Malariometric update for the rainforest and savanna of Ashanti region, Ghana. Ann Trop Med Parasitol 2000, 94:15-22.

19. Snounou G, Viriyakosol S, Zhu XP, Jarra W, Pinheiro L, do Rosario VE, Thaithong S, Brown KN: High sensitivity of detection of human malaria parasites by the use of nested polymerase chain reaction. Mol Biochem Parasitol 1993, 61:315-320.

20. Eggelte TA: Production of monoclonal antibodies against antimalarial drugs for use in immunoassays. In The Validation of Chemical and Immunochemical Tests for Antimalarials in Body Fluids. International Monograph Series 3. Edited by Navaratnam V, Payne D. Penang: Universiti Sains Malaysia; 1990:35-63.

21. Finnström O: Studies on maturity in newborn infants. IX. Further observations on the use of external characteristics in estimating gestational age. Acta Paediatr Scand 1977, 66:601-604.

22. Blumenfeld OO, Patnaik SK: Allelic genes of blood group antigens: a source of human mutations and cSNPs documented in the Blood Group Antigen Gene Mutation Database. Hum Mutat 2004, 23:8-16.

23. Fried M, Muga RO, Misore AO, Duffy PE: Malaria elicits type 1 cytokines in the human placenta: IFN-gamma and TNF-alpha associated with pregnancy outcomes. J Immunol 1998, 160:2523-2530.

24. Fried M, Nosten F, Brockman A, Brabin BJ, Duffy PE: Maternal antibodies block malaria. Nature 1998, 395:851-852.

25. Beeson JG, Brown GV, Molyneux ME, Mhango C, Dzinjalamala F, Rogerson SJ: Plasmodium falciparum isolates from infected pregnant women and children are associated with distinct adhesive and antigenic properties. $J$ Infect Dis 1999, 180:464-472.

26. Jarra W, Snounou G: Only viable parasites are detected by PCR following clearance of rodent malarial infections by drug treatment or immune responses. Infect Immun 1998, 66:3783-3787.

27. Mockenhaupt FP, Ulmen U, von Gaertner C, Bedu-Addo G, Bienzle U: Diagnosis of placental malaria. J Clin Microbiol 2002, 40:306-308.

28. Degarege A, Medhin G, Animut A, Legess M, Erko B: Association of ABO blood group and $P$. falciparum malaria related outcomes: a crosssectional study in Ethiopia. Acta Trop 2012, 123:164-169.

29. Barragan A, Kremsner PG, Wahlgren M, Carlson J: Blood group A antigen is a coreceptor in Plasmodium falciparum rosetting. Infect Immun 2000, 68:2971-2975.

30. Rogerson SJ, Beeson JG, Mhango CG, Dzinjalamala FK, Molyneux ME: Plasmodium falciparum rosette formation is uncommon in isolates from pregnant women. Infect Immun 2000, 68:391-393.

31. Chen Q, Heddini A, Barragan A, Fernandez V, Pearce SF, Wahlgren M: The semiconserved head structure of Plasmodium falciparum erythrocyte membrane protein 1 mediates binding to multiple independent host receptors. J Exp Med 2000, 192:1-10.

32. Fried M, Duffy PE: Two DBLgamma subtypes are commonly expressed by placental isolates of Plasmodium falciparum. Mol Biochem Parasitol 2002, 122:201-210.

33. Fried M, Duffy PE: Adherence of Plasmodium falciparum to chondroitin sulfate A in the human placenta. Science 1996, 272:1502-1504.

34. Beeson JG, Rogerson SJ, Cooke BM, Reeder JC, Chai W, Lawson AM, Molyneux ME, Brown GV: Adhesion of Plasmodium falciparum-infected erythrocytes to hyaluronic acid in placental malaria. Nat Med 2000, 6:86-90.

35. Rogerson SJ, Novakovic S, Cooke BM, Brown GV: Plasmodium falciparuminfected erythrocytes adhere to the proteoglycan thrombomodulin in static and flow-based systems. Exp Parasitol 1997, 86:8-18.

36. Blann AD, Daly RJ, Amiral J: The influence of age, gender and ABO blood group on soluble endothelial cell markers and adhesion molecules. $\mathrm{Br} J$ Haematol 1996, 92:498-500.

37. Wolofsky KT, Ayi K, Branch DR, Hult AK, Olsson ML, Liles WC, CsertiGazdewich CM, Kain KC: ABO blood groups influence macrophagemediated phagocytosis of Plasmodium falciparum-infected erythrocytes. PLoS Pathog 2012, 8: 1002942.

38. Ordi J, Ismail MR, Ventura PJ, Kahigwa E, Hirt R, Cardesa A, Alonso PL, Menendez C: Massive chronic intervillositis of the placenta associated with malaria infection. Am J Surg Pathol 1998, 22:1006-1011.

doi:10.1186/1475-2875-13-289

Cite this article as: Bedu-Addo et al: Reduced prevalence of placental malaria in primiparae with blood group O. Malaria Journal 2014 13:289. 